\title{
Mudanças na prática docente numa perspectiva de desenvolvimento pessoal e profissional
}

\section{Changes in teaching from a personal and Professional point of view}

\author{
Solange Mary Moreira SANTOS*
}

RESUMO: Neste estudo, objetiva-se investigar as mudanças que ocorreram na prática docente de cinco professoras da rede pública de ensino do município de SantanópolisBahia, que participaram do Projeto TRANSE-Transformando a Educação do Ensino Fundamental, desenvolvido pela UEFS - Universidade Estadual de Feira de Santana. Nessa pesquisa, optou-se pela metodologia qualitativa do tipo etnográfico, por exigir uma descrição pormenorizada das situações e vivências culturais dos sujeitos no contexto da pesquisa. Para tanto, utilizou-se dos postulados de Garcia, Pérez Gómez, Nóvoa e Zeichner, os quais embasam a idéia de que a formação continuada é entendida como importante elemento de mudança das práticas pedagógicas. Nos achados dessa pesquisa, foram constatadas mudanças na prática docente desses sujeitos, assim como dificuldades que limitam essas mudanças. Além disso, foi reconhecida a importância que esses sujeitos depositaram no Projeto TRANSE. Finalmente, são apresentadas propostas, com vistas a um repensar dos programas de formação continuada.

Palavras-chave: mudanças, prática docente, formação continuada

ABSTRACT: This study deals with the changes that have occurred in the work of five state school teachers in the town of Santanópolis - Bahia. These teachers took part in the TRANSE Project - Transforming Elementary and Secondary Teaching - sponsored by UEFS - Feira de Santana State University. This research opted for the qualitative methodology of the ethnographic kind, because it highlights a detailed description of situational and cultural experiences lived by those group of teachers. The principles of Garcia, Pérez Gómez, Nóvoa e Zeichner, which base themselves on the belief that ongoing formation is seen as an important element for bringing about change in the teaching practice. The results of this research have shown that there are changes in the

* Doutora em Educação (Currículo), pela PUC-SP. Professora da Universidade Estadual de Feira de Santana - UEFS/Bahia. Email: solange.santos@ig.com.br

Olhar de professor, Ponta Grossa, 8(2): 47-63, 2005. 
teaching of the subjects as well as difficulties that limit these changes. In addition to this, the subjects gave a lot of importance to the TRANSE Project. New propositions were presented with a view to giving new thought to the programs of on-going formation.

Key words: changes, pedagogical practices, on-going formation

No momento atual, em plena era de grandes mudanças na sociedade, decorrentes, em grande parte, do desenvolvimento tecnológico, sobretudo da Informática e das Telecomunicações, vêm se discutindo, com mais intensidade, a questão da formação de professores. Essa formação tem como base, além de outras questões, o problema da defasagem entre a preparação oferecida pelas escolas de formação de professores e a realidade da atividade prática futura. Por conseguinte, é criticada a inadequação desses cursos na preparação de profissionais competentes, para o exercício de suas atividades.

Pesquisas sobre essa formação têm demonstrado que tais cursos não estão conseguindo preparar os professores para acompanhar as mudanças cada vez mais rápidas, da ciência, dos avanços tecnológicos e da globalização. Provavelmente, devido à deficiência de formação, os professores não se apercebem de que o modo de vida e os procedimentos padronizados e repetitivos vêm sendo substituídos, de forma rápida, pela automação, pela robótica, pela informação. Estes fatores implicam novos horizontes na formação de profissionais das diferentes áreas de conheci- mento e, sobretudo, na formação de professores.

Esses fatores fizeram surgir o discurso e a prática da formação continuada, redimensionando o papel da formação inicial de professores, no desenvolvimento da sua competência para ensinar. Assim, se o curso de formação inicial é condição para um sujeito tornar-se professor, ser professor implica estar em formação contínua.

Assim, ressalto que os programas de formação continuada têm de buscar, simultaneamente, o exercício constante de exame da realidade a partir de teorias, e, a revisão das teorias, a partir da prática docente. Para tanto, é imprescindível a construção de um paradigma que traga, para esses cursos, a presença complexa do cotidiano da profissão, examinando-o, questionando-o para transformá-lo.

Nessa perspectiva, no contato com os cursos de formação de professores e, também, a partir dos estudos e pesquisas desenvolvidos no Núcleo de Estudos e Pesquisa sobre a Formação do Professor (NUFOP), da Universidade Estadual de Feira de Santana (UEFS), venho notando que as instituições formadoras nem sempre estimulam a postura do professor, como sujeito e construtor do conhe- 
cimento. Essa concepção, no entanto, deveria ser o pressuposto básico, no processo de formação de professores.

A idéia de que o exercício da profissão é um locus poderoso da formação do professor assume contornos bastante claros para mim, talvez como síntese de elaborações que têm me acompanhado há algum tempo. Desse modo, neste trabalho, concentrome na formação continuada que, sem dúvida, é o cotidiano de trabalho da UEFS e do NUFOP.

Nesse sentido, a UEFS, através da Pró-Reitoria de Extensão, vem solicitando, constantemente, a colaboração dos professores do Departamento de Educação, com vistas a desenvolver projetos e organizar trabalhos de capacitação e acompanhamento em serviço dos professores que participam do Projeto Transformando a Educação do Ensino Fundamental (TRANSE). Tais trabalhos têm me levado a constatar que há uma tendência em priorizar a problemática da formação de professores, numa perspectiva continuum. Essa idéia vem sendo amplamente discutida, uma vez que muitos pesquisadores estão chegando à conclusão de que os saberes docentes são, na sua maioria, constituídos na prática, na experiência em sala de aula (TARDIF; LESSARD; LAHAYE, 1991). Disso resulta, inevitavelmente, a advertência sobre a importância de se investir numa profissionalização que acompanhe a própria prática docente.
Assim, com o propósito de investigar e analisar as mudanças que ocorreram na prática docente das professoras que participaram do Projeto TRANSE-UEFS, esta pesquisa levantou informações que me permitiram verificar o que levou essas professoras a ingressarem no referido Projeto; como se sentiram durante esse período; que mudanças verificaram em suas práticas e até que ponto essas mudanças resultaram, mesmo, da participação no Projeto.

\section{A INVESTIGAÇÃO}

A intenção de investigar o Projeto TRANSE se dá, principalmente, pelo meu interesse em avaliar essa iniciativa, o que ela pode contribuir nas discussões atuais sobre a formação continuada, como recurso para a melhoria de currículo e práticas docentes, notadamente, para a elevação da qualidade de ensino na escola pública. Além do mais, esse Projeto, que já funciona há 19 anos, nunca passou por um processo de avaliação, nem pela Instituição e nem pela comunidade de que dele participa. Necessário se torna, ainda, uma tentativa de verificação do alcance do objetivo que é a redução do fracasso escolar, sob pena de o projeto transformar-se num mito mantido pelo prestígio social e político, no âmbito interno e externo.

É nessa perspectiva que essa investigação buscou pistas, observou comportamentos, modos de percepção, ações, discursos e atitudes que 
me permitiram delinear as alterações das vivências docentes no Projeto TRANSE. Os instrumentos metodológicos utilizados para coleta de dados foram: a entrevista e a observação. Eles permitiram-me uma avaliação dos mecanismos de desenvolvimento desse Projeto e o seu funcionamento como elemento limitador e/ou possibilitador de mudança da prática dos docentes envolvidos.

Foi assim que, cheguei ao trabalho de campo, definindo a Etnografia como metodologia para o desenvolvimento da pesquisa. Ao mesmo tempo e, posteriormente, fui analisando os dados coletados, chegando, assim, a algumas sínteses. Essas me conduziram à sistematização de um processo reflexivo inerente ao ser humano, especialmente àqueles que atuam na profissão docente e que podem indicar elementos a serem considerados, na organização do trabalho nas escolas, tendo em vista a construção da competência e de sucessos coletivos.

Quando fiz a escolha por esse tipo de investigação já tinha clareza da importância de acompanhar o dia-adia das professoras-coordenadoras das séries iniciais do Ensino Fundamental, do município de Santanópolis ${ }^{1}$, para focalizar as diversas situações vividas por elas na escola, na sala de aula, nas reuniões de planejamento com a coordenadora geral e com outros professores do município.
Trata-se de um município que já vivencia a experiência com o TRAN$\mathrm{SE}$, há aproximadamente 15 anos. Entretanto, seus professores ainda reconhecem que não sabem fazer transposições didáticas dos saberes nele trabalhados para o cotidiano da sala de aula. Tal constatação está evidenciada nos relatórios de 1996 e 1997: "embora muitos professores sintamse mais preparados, reconhecem que ainda têm muitas dificuldades para desenvolver atividades que aprenderam nos cursos de formação, sobretudo as atividades de leituras" (depoimento dos professores).

Optei por trabalhar com os 5 (cinco) professoras "multiplicadoras", porque têm a função de repassar, em sua escola, os saberes que são adquiridos, durante os encontros na Universidade. Essas professoras dão assistência a todas as escolas envolvidas nesse Projeto. Segundo a Secretária de Educação, eles foram escolhidos para serem "multiplicadores":

Pelo fato de a comunidade considerar que eles têm preocupação em realizar um bom ensino, pelo período de permanência desses professores no Projeto e também participarem das atividades de acompanhamento do Projeto e dizerem já ter experiência a ponto de poderem exercer o papel de condutores do processo de formação em seus municípios.

${ }^{1}$ Município distante $36 \mathrm{~km}$ de Feira de Santana. 
Assim, esse trabalho de pesquisa está proporcionando subsídios que ajudarão a aprofundar questões sobre esse tipo de formação, contribuindo, também, com a busca de elementos que possam nortear futuras ações.

\section{MUDANÇAS OBSERVADAS NA PRÁTICA DOCENTE DOS SUJEI- TOS DA PESQUISA}

Nessa pesquisa, vislumbrei a mudança como a capacidade de o professor organizar diferentes idéias, visando construir outras maneiras de conceber e interpretar o trabalho docente e, assim, orientar-se para objetivos de formação bem mais amplos. Para tanto, os professores terão de contemplar não apenas aqueles itens usuais de um programa de ensino, mas, sobretudo, as dimensões da cultura que hoje definem o verdadeiro conhecimento. Desse modo, os processos de mudança devem atender, necessariamente, ao que Garcia (1999, p. 47) tem chamado de "dimensão pessoal da mudança", ou seja, o envolvimento do professor em processos reflexivos sobre si mesmo, no contexto profissional, com previsíveis implicações no seu autoconhecimento, como pessoa e profissional.

Por conta disso, a mudança no campo profissional não pode dissociar-se das transformações do campo pessoal. Isso implica que o professor tenha uma nova maneira de planejar, ensinar, organizar o conhe- cimento, de avaliar e de se relacionar com o aluno. Significa, ainda, que a mudança só se desenvolve dentro das escolas se for concretizada no professor. Por essa razão, é necessário dar atenção especial à dimensão pessoal, à maneira de pensar e agir dos professores.

Reforçando, Garcia (1999,p. 47), nas investigações sobre o pensamento dos professores, tem demonstrado que eles:

Não são técnicos que executam instruções e propostas elaboradas por especialistas. Cada vez mais se assume que o professor é um constru-tivista que processa informações, toma decisões, gera conhecimento prático, possui crenças e rotinas que influenciam sua atividade profissional.

É preciso ter presente, nesse processo de mudanças, a dimensão da aprendizagem do professor, uma vez que num processo de mudança é importante envolvê-lo desde sua fase de elaboração até prever um programa de formação continuada para responder aos desafios que eles enfrentarão no seu cotidiano. Conforme assevera Pacheco (1996, p. 152), esse tipo de programa deve comportar a existência dos seguintes pressupostos: "capacidade estratégica de tomada de decisão; projectos de investigação/acção; dispositivos de avaliação de acções de inovação; condições escolares favoráveis". Sem atender a essas condições, a reforma não 
sairá do papel ou será implantada de forma caricata, resultando num quadro geral de mal-estar docente ${ }^{2}$ (ESTEVE, 1995).

A partir dessas concepções, apresento uma síntese das principais mudanças constatadas na prática docente das professoras, sujeitos da pesquisa, que participaram dos encontros do TRANSE, e confirmadas pelos depoimentos e extratos das observações:

- As professoras, na elaboração do planejamento, refletiam coletivamente sobre as atividades desenvolvidas, durante os programas de formação continuada, e viam a possibilidade de adequá-las à sala de aula;

- As professoras mudaram a forma de trabalho, em relação à aplicação dos conteúdos, das atividades e das avaliações trabalhadas em sala de aula e, com isso, os alunos passaram a ser mais participativos $e$ questionadores;

- Mudou a relação professoral professora; professora/aluno, famílias e coletividades locais com isso passaram a estudar e discutir coletivamente as atividades trabalhadas no TRANSE;

- As professoras começaram a se dedicar mais à leitura de livros, de jornais e de revistas, que contribuíram, desse modo, para mudanças na sua sala de aula;
- Houve mudanças na vida pessoal das professoras: como vontade de voltar a estudar, ou satisfação pessoal com o trabalho realizado;

- Houve mudanças em relação à vida profissional: aprendizagem de novas formas de realizar o trabalho docente, ampliação de conhecimentos; maior experiência profissional, refletida em melhor qualidade do trabalho desenvolvido em classe, capacidade de se expressar, destacando-se novas formas de convivência com as colegas.

Esses dados proporcionaram a oportunidade de confirmar a percepção que tive das professoras, desde o início das observações na sala de aula, pela preocupação demonstrada com o desenvolvimento do próprio trabalho, pelo esforço para construir uma "prática diferenciada" (PERRENOUD, 2002), que servisse de alavanca para as transformações de suas próprias ações. A diferença entre as professoras está, principalmente, na maneira de ensinar de cada uma delas. Por exemplo, observei que todas conseguem, a seu modo, o envolvimento do aluno com a própria aprendizagem, evidenciado na interação estabelecida entre elas próprias (professoras), entre elas e o aluno face à construção do conhecimento.

\footnotetext{
${ }^{2}$ ESTEVE, J. in NÓVOA, A. expressão mal-estar docente (malaise enseignant, teacher burnout) emprega-se para descrever os efeitos permanentes, de caráter negativo, que afectam a personalidade do professor como resultado das condições psicológicas e sociais em que exercem a docência devido à mudança acelerada (1995, p. 98).
} 
Percebo, desse modo, que essa "prática diferenciada" não tem um modelo definido, mas é construída a partir da interferência que as professoras recebem do habitus (BOURDIEU, 1972 e PERRENOUD, 1993, 1999), das mais variadas influências do sistema educacional, do contexto das escolas com todos os determinantes que possuem, da reflexão que realizam e dos estudos efetivados. Nesse caso, é possível entender o habitus como fruto do que cada professora vivenciou e ainda vivencia, em sua classe atual, em outras classes ou em diversos grupos, entrando em um espírito cooperativo com outros atores.

Esse processo requer, por parte das professoras envolvidas na escola, uma atitude permanente e sistemática de reflexão (SCHÖN, 1997), sendo decisiva nesse processo, a capacidade de inovar, de negociar e de regular a prática. A prática reflexiva passa por uma análise sobre a experiência, favorecendo a construção de novos saberes e a ressignificação dos saberes já construídos.

Entretanto, Perrenoud (2002, p. 13) assevera que todos nós refletimos "na ação" e "sobre a ação" e, nem por isso, nos tornamos profissionais reflexivos. Analisando essa questão o autor, assim afirma:

Visando chegar a uma verdadeira prática reflexiva, essa postura deve se tornar quase permanente, inserir-se em uma relação ana- lítica com a ação, a qual se torna relativamente independente dos obstáculos encontrados ou das decepções. Uma prática reflexiva pressupõe uma postura, uma forma de identidade, um habitus. Sua realidade não é medida por discursos ou por intenções, mas pelo lugar, pela natureza e pelas conseqüências da reflexão no exercício cotidiano da profissão, seja em situação de crise ou de fracasso seja em velocidade de cruzeiro.

Desse modo, concordando com o autor, acredito que as professoras, sujeitos dessa pesquisa, quando estavam "em ação" e "sobre ação" (SCHÖN,1997), não podiam ser consideradas profissionais reflexivos. $\mathrm{Na}$ verdade, elas estavam realizando uma "reflexão episódica" (PERRENOUD, 2002), casual, sobre a sua ação.

Nessa perspectiva, considero que os professores que apresentam postura reflexiva assumem as situações práticas como espaços de diálogo e intercâmbio entre as diversas dimensões do conhecimento e os diferentes atores na produção de novos conhecimentos, indo além das regras. As questões da prática requerem decisões, comprometimentos e respostas.

Sob o ponto de vista de Garcia (1997) a reflexão da ação é considerada um melhor instrumento de aprendizagem e de formação, permitindo, de maneira flexível e aberta à compreensão e a atuação na e para a realidade. 
O profissional da educação, no contato com a situação prática, adquire e constrói novos saberes, sistematiza conceitos, assim como vivencia o processo dinâmico da aprendizagem, porque ele pesquisa, aprende e ensina. Esses três processos são intrinsecamente construídos de maneira a distinguir a concepção da reprodução, no ato educativo.

Os professores criam novas possibilidades de aprendizagem, quando eles estruturam sua atuação na reflexão. Também, nas relações sociais, eles se redefinem, porque a reflexão coletiva oportuniza as relações solidárias, exigindo uma reorganização do trabalho pedagógico. Considero, ainda, que o ato reflexivo não se desassocia da necessidade e da importância do autoconhecimento, ou seja, da consciência que cada professor tem de si mesmo.

Em acréscimo, este estudo indica as influências que os programas de formação continuada têm na vida profissional das professoras, principalmente, para a implementação de mudanças em suas práticas pedagógicas. Sob a ótica das professoras envolvidas nesta pesquisa, pude constatar que essas mudanças, mesmo em níveis e graus diferenciados, estão relacionadas à participação nesses programas, principalmente ao Projeto TRANSE. A seguir, uma síntese do que relataram as professoras:

- Começaram a participar de programas de formação continuada por indicação do Prefeito ou da Secre- tária de Educação do Município porque estes acreditavam que as professoras precisavam se adequar às mudanças que o momento exigia;

- As próprias professoras constataram, depois, que precisavam se atualizar, porque estava ocorrendo mudança na Educação, principalmente, com a aprovação da $L D B n^{\circ}$ 9394/96 e as inovações no mundo moderno;

- Elas relataram que, no desenvolvimento de atividades, o TRANSE propiciava a troca de experiências entre os Municipios;

- Disseram, também, que no ano de 1999, o TRANSE passou a trabalhar com os teóricos que dão suporte à prática educativa.

Esses relatos indicam que a formação continuada foi significativa para o redimensionamento profissional das professoras, uma vez que elas mergulharam cada vez mais, lançando-se na busca constante de novos conhecimentos e de recursos adequados para o aperfeiçoamento da própria prática.

\section{DIFICULDADESQUE LIMITAMAS MUDANÇAS NA PRÁTICA}

Apesar de reconhecerem as mudanças na prática docente, as professoras falaram que, mesmo com as orientações dos programas de formação continuada, tinham dificuldades em desenvolver uma prática que buscasse a transformação. Essas dificuldades se deviam, notadamente, ao fato 
de que esses programas não levam em consideração as observações empíricas e metódicas sobre as práticas, isto é, sobre o trabalho real das professoras no dia-a-dia, em sua diversidade e ambiente atual. Esses cursos estavam baseados mais em uma visão prescritiva das atividades do que em uma análise precisa da realidade. Nesse sentido, Perrenoud (2002, p. 17) assevera que: "para fazer as práticas evoluírem, é importante descrever as condições e as limitações do trabalho real dos professores. Essa é a base de toda estratégia de inovação".

Desse modo, quando se elabora um plano de formação, seja inicial ou continuada, é preciso realizar uma profunda pesquisa sobre as práticas, oferecendo ao investigador uma imagem realista dos problemas que ele precisa resolver todos os dias, dos dilemas que ele vai enfrentar, das decisões que vai tomar, dos gestos profissionais que vai realizar.

As professoras, por terem consciência da fragilidade da sua formação, de maneira geral e, em especial, no que se refere ao saber pedagógico, estavam sempre buscando, através dos programas de formação continuada, suprir as lacunas sentidas, para encarar os óbices que tinham que enfrentar, quer previsto ou não, na complexa vida de sala de aula. É possível constatar, então, que as professoras procuravam assumir a formação continuada movidas pela necessidade de aprender a aprender, comprometidas em se transformar para trans- formar os alunos sob suas responsabilidades.

Nesse sentido, as professoras demonstraram ter encontrado dificuldades em desenvolver um trabalho transformador, o que se convertem em álibis para a resistência às implementações de novas propostas, detectadas neste estudo, através das seguintes dificuldades apontadas:

- Trabalham em classes multisseriadas;

- Atividades propostas pelo TRANSE que nem sempre se adequavam à realidade do Município;

- Ausência de biblioteca para elas realizarem pesquisas;

- Falta de material didático para elas fazerem os repasses;

- Consideram o trabalho desenvolvido pelas estagiárias dos cursos de Licenciatura da UEFS inadequado;

- A coordenação do TRANSE organizava os grupos de trabalho sem levar em consideração as necessidades e os interesses das professoras;

- O Projeto dá ênfase ao aspecto metodológico;

- Não há relação da teoria com a prática;

- Não há clareza de como se desenvolve um trabalho interdisciplinar;

- Os encontros do TRANSE acontecem fora do "locus" de trabalho das professoras;

- A organização e gestão das escolas não favorecem o trabalho pedagógico; 
- Falta de preparação formal, quer dos formadores universitários (estagiários dos cursos de Licenciaturas), quer dos coordenadores das escolas;

- Não são levadas em consideração as diferenças individuais e dificuldades de aprendizagens.

Além disso, esse programa de formação continuada não tem atentado para vários fatores importantes na sua elaboração e implementação, como as reais condições de trabalho dos professores e, principalmente, a falta de conhecimento das reais condições de organização e funcionamento das escolas, bem como dos vários conflitos que ocorrem cotidianamente em seu interior. Programas que são elaborados, a partir de uma concepção de educação e passam a ser instrumento que dá sustentação às políticas hegemônicas do Estado. Tais programas têm apresentado propostas pedagógicas que não dão conta dos problemas educacionais, haja vista a falta de uma visão crítica da educação, como fenômeno histórico e social.

\section{A IMPORTÂNCIA DO PROJETO "TRANSE" PARA OS SUJEITOS DAPESQUISA}

Este estudo dá condições de se perceber que, apesar de todos os problemas apresentados pelas condições norteadoras do Projeto TRANSE, bem como as estratégias utilizadas para $\mathrm{o}$ seu desenvolvimento, o referido Projeto foi considerado pelas professo- ras como sendo uma iniciativa relevante para o aprimoramento da prática e para resolução de problemas cotidianos. Elas se sensibilizaram com as novas propostas, procurando alterar crenças, concepções e conhecimentos, dispondo-se a alterar sua prática com base nos trabalhos realizados nos encontros. Elas disseram em seus depoimentos:

Participar do TRANSE foi importante, porque nos ajudou a abrir os olhos sobre as mudanças que estavam ocorrendo na educação, principalmente, em relação às reformas educacionais. OTRANSE tem sido um estímulo para a gente questionar a prática .

O TRANSE foi o primeiro projeto de formação continuada de que participei. Achei-o importante, porque a gente fica aqui, em Santanópolis, muito distante das mudanças que estão ocorrendo na educação.

O Projeto TRANSE me deu oportunidade para ampliar o meu conhecimento. Passei a ver as coisas com uma nova visão. Hoje, eu consigo perceber que tenho que estar atenta às transformações que estão ocorrendo na sociedade, porque elas chegam até a escola, através da televisão, dos livros, dos jornais e das revistas.

O TRANSE foi importante porque contribuiu para mudar as minhas aulas. Antes, no Municipio, a 
gente não tinha a quem pedir sugestão para planejar aulas mais motivadoras e, com o TRANSE, as aulas se tornaram dinâmicas e significativas.

Se a gente não participa dos projetos de formação continuada, seja na UEFS ou em qualquer outro lugar, ficamos no Município distante de saber quais são as mudanças e o que devemos aplicar em nossa sala de aula.

Também, nas observações, pude constatar que as ações das professoras apontavam para uma prática a caminho das mudanças. A reflexão utilizada por elas nos momentos de impasse as ajudava a diminuir a margem de erros ou desacertos nos atos formativos, além de evidenciar suas responsabilidades, o que as levavam a vislumbrar as conseqüências dos seus atos, uma vez que esse processo reflexivo lhes permitia estar fazendo revisões contínuas nas suas práticas.

Segundo as professoras, as ações de formação continuada eram mediadas pelas concepções e práticas que desenvolveram em suas carreiras, fazendo com que, por vezes, as interpretações realizadas levassem para direcionamentos defendidos pelas propostas curriculares. Mesmo assim, as professoras apontavam para as principais fontes geradoras de reflexão e passíveis de proporcionarem mudanças em suas práticas, como as trocas de experiências e as discussões voltadas para o cotidiano da sala de aula.

Dessa maneira, penso que a formação continuada tem propiciado uma reflexão, mesmo que "episódica", sobre os aspectos do trabalho docente cotidiano e dos saberes nele constituído. Possibilitando, assim, o avanço no desenvolvimento profissional das professoras, ao mesmo tempo em que alimenta o conhecimento da realidade dos formadores que com eles interagem, fornecendo-lhes elementos para a atuação nos cursos de formação inicial. Entretanto, concordando com Perrenoud (2002), é possível afirmar que só um formador reflexivo pode formar professores reflexivos, porque ele utiliza a reflexão que já está consolidada em torno de uma pergunta, de um debate, de uma tarefa ou de um fragmento de saber.

Nesse sentido, o processo interativo reflexivo implica numa convivência entre o formador e formandos, numa relação de colaboração e de partilha. A figura do formador aparece, então, como apoio técnico de quem já percorreu mais o caminho da docência, mas não se configura como o sabedor das coisas. A ênfase é nos saberes dos professores envolvidos, que também pode ter caráter científico e didático. Esse processo de formação assumida na interatividade $\mathrm{e}$ no dinamismo é ressignificado por Nóvoa (1997, p. 26) como:

(...) a troca de experiência e a partilha de saberes consolidam 
espaços de formação mútua, nos quais cada professor é chamado a desempenhar, simultaneamente, o papel de formador e de formando. $O$ diálogo entre os professores é fundamental para consolidar saberes emergentes da prática profissional.

A análise das necessidades emergentes do corpo docente demanda ações reflexivas como ressalta Rodrigues e Esteves (1993, p. 22) "que o formador apóie o formando na "construção" das suas necessidades, mediante a criação de espaços/momentos favoráveis à consciencialização dos seus problemas, dificuldades e interesses, ao longo da formação".

Para essas autoras, essa análise torna-se parte integrante do processo formativo, sendo o formando concebido não como mero objeto de formação, mas um sujeito privilegiado desta. A essência na formação continuada é a construção coletiva do "saber" e a discussão crítico-reflexiva do "saber fazer".

Para Pimenta, Garrido e Moura (2001, p. 2) os programas de formação continuada deveriam se constituir não só em um processo de aperfeiçoamento profissional, mas também em um processo de transformação da cultura escolar, na qual novas práticas participativas e de gestão democrática vão sendo incorporadas, implementadas e consolidadas. Nesse sentido, concordo com os autores quan- do asseveram que "a formação de professores reflexivos pode contribuir para configurar um projeto pedagógico emancipatório".

Para que a reflexão possa se enraizar, os referidos pesquisadores ressaltam que é preciso haver certas condições no ambiente de trabalho escolar e nas relações entre o grupo de "formadores de educadores" e de professores. "É preciso aceitar que o professor precisa ter mais controle sobre as condições de trabalho. É preciso valorizar ações conjuntas, experiências cotidianas dos professores, projetos coletivos, capazes de modificar os contextos escolares" (PIMENTA, GARRIDOEMOURA 2001,p. 2), contribuindo para que os professores assumam atitudes desencadeadoras de mudanças.

A iniciativa de formação ligada à resolução de problemas reais, com ajuda dos professores e dentro do espaço da escola, é uma perspectiva na capacitação docente. A negociação de parceiros na formação centrada na escola demanda ações programadas de trabalho coletivo e estudo de casos originários das expectativas dos próprios docentes.

Como pondera Imbernón (2001, p. 86), a formação de professores centrada na escola:

(...) converte-se em um processo de autodeterminação baseado no diálogo, na medida em que se implanta um tipo de compreensão compartilhada pelos partici- 
pantes, sobre as tarefas profissionais e os meios de melhorá-las, e não um conjunto de papéis e funções que são aprimoradas mediante normas e regras técnicas

No entanto, nada impede que os professores busquem outros conhecimentos de interesses em diferentes instituições, uma vez que eles poderão trazer o conhecimento de que se apropriaram para socializar com os colegas. É importante, mesmo, valorizar e estimular essa iniciativa.

Também, deve ser discutido, dialógica e intensamente, o encontro do equilíbrio entre as necessidades do grupo de docentes e da Universidade. Esta proposição demanda um repensar na formação, pois, além de continuada, necessita contemplar ações coletivas, associar a formação com a pesquisa, a reflexão que relacione a teoria à prática e a capacitação docente como um processo desenvolvido na própria escola.

Por conseguinte, é preciso rever as relações entre a universidade e a escola, esta compreendida como um campo no qual, por meio da reflexão sobre a prática, é possível desenvolver um diálogo crítico e produtivo, que vise ao crescimento intelectual dos professores que nela trabalham.

Nessa perspectiva, é fundamental que o Projeto TRANSE leve em conta o contexto real dessas professoras, marcado por classes multisseriadas. Para isso, é fundamental que ele se proponha a orientar as profes- soras para trabalhar com a diversidade de alunos existentes nessas classes. Em conseqüência dessa necessidade, é preciso rever o modelo de formação vigente, buscando estabelecer nexos com as atuais necessidades formativas. Por conta disso, faz-se necessário compreender que as professoras que chegam a esses cursos trazem expectativas, vivências e histórias de vida diferenciadas, que precisam ser reconhecidas e trabalhadas no plano das dimensões pessoais, culturais e sociais.

Considero relevante, ainda, que o referido Projeto, em sua proposta, crie as bases para uma "transposição didática" (PERRENOUD, 1993) a partir das práticas efetivas e da necessidade de transformações, respeitando a diversidade de condições de exercício da profissão. Para tanto, os formadores de professores devem ter clareza suficiente de que precisam, nessa proposta, propiciar ao professor o saber transformar o conteúdo apreendido, em conteúdo escolar.

Sei que grande parte da responsabilidade do TRANSE, no município de Santanópolis, depende da prática dos professores, em sala de aula, prática que não pode ser neutra e nem descompromissada com os problemas sociais que modelam as suas experiências de ensino. Nesse sentido, os professores precisam pensar sobre as dimensões sociais e políticas que afetam o seu cotidiano, a sua prática de ensino, e mostrar que podem tomar decisões sobre a mudança. 
Desse modo, estou propondo que a prática reflexiva seja concebida como eixo curricular desse processo, configurando, assim, uma nova epistemologia da prática. Segundo Geraldi, Messias e Guerra (1998) uma proposta de formação, tendo como eixo a reflexão sobre a prática, significa assumir alguns pressupostos ou implicações que derivam deste eixo:

A constituição de uma nova prática vai exigir sempre uma reflexão sobre a experiência de vida escolar do professor, sobre suas crenças, posições, valores, imagens e juízos pessoais;

A formação é um processo que se dá durante toda a carreira docente e se inicia muito antes $d a$ chamada formação inicial, através da experiência de vida;

Cada professor é responsável pelo seu próprio desenvolvimento;

É importante que o processo de reflexão ocorra em grupo, para que se estabeleça a relação dialógica;

A reflexão parte da e é alimentada pela contextualização sóciopolítica e cultural. (op cit, p. 248-249).

Sendo assim, os cursos de formação continuada deveriam trazer para si a reflexão contextualizada, como principal instrumento da profissão. Essa formação deve, também, estar intimamente articulada ao projeto educativo da escola, incorporando à prática trabalhos de investigaçãoação-reflexão que possam, de fato, contribuir para a melhoria da qualidade de ensino. Além disso, devem incluir programas que tenham como objetivo o desenvolvimento profissional. Nesse contexto, é urgente analisar a cultura organizacional das escolas e captar as formas pelas quais se dá sua interação com o meio social e político e as inter-relações que estabelecem com a comunidade. Este conhecimento da cultura organizacional deve acompanhar o processo de construção coletiva dos projetos da escola.

\section{PROPOSTAS PARA REPENSAR OS PROGRAMAS DE FORMAÇÃO CONTINUADA}

Finalmente, a partir da análise e reflexão sobre as questões de mudanças, apresento alguns aspectos, que devem servir de base para a formulação e/ou reformulação de propostas de formação continuada, especialmente, do Projeto TRANSE.

- Elaborar um diagnóstico da situação concreta vivenciada pelos professores no Município. Nos programas de formação continuada, o conhecimento deve se reportar à prática e ao conjunto de problemas e interrogações que surgem no diálogo com as situações conflituosas do cotidiano educativo.

- Rever o atual modelo de forma- 
ção e estabelecer outras formas para solucionar tal problema, com vistas a uma retomada do processo de formação continuada, em bases mais seguras e mais coerentes com as atuais necessidades formativas.

- Participar contínua e colaborativamente, das diversas experiências, analisando-as, experimentando-as, avaliando-as e modificando-as, juntamente com outros colegas ou membros da comunidade.

- Construir programas de formação continuada que integrem um conjunto diversificado de conteúdos, uma vez que grupos de professores estão interessados nessa pluralidade de dimensões formativas.

- Conceber a prática reflexiva como eixo curricular desse processo, configurando uma nova epistemologia da prática. Assim, o curso deverá eleger a reflexão como principal instrumento de trabalho.

- Valorizar as experiências culturais e os conhecimentos prévios dos professores, ajudando-os a refletir sobre o próprio trabalho e o confrontando com os resultados de aprendizagem obtidos.

- Acatar as sugestões dos professores acerca de suas necessidades relativas a planejamento, conteúdo, metodologia e avaliação.

- Implementar cursos solicitados pela comunidade escolar, nos municípios e, na medida do possível, nas escolas.

- Promover um trabalho coletivo, articulado entre todos os atores da comunidade escolar e familiar, para discutir concepções, compartilhá-las, ler as divergências e as convergências e, mediante esses confrontos, reconstruir o trabalho.

- Elaborar projetos de trabalho, de caráter inovador e vinculá-los à formação, mediante estratégias de intervenção do professor na sala de aula e na escola.

- Propiciar um ambiente formativo de colaboração e interação social, isto é, compartilhar problemas, fracassos e sucessos entre colegas.

- Buscar articulação democrática entre a Secretária de Educação, Direção de Escola, Coordenadores e Professores, visando ao desenvolvimento de um trabalho coletivo.

A partir desses aspectos, proponho que a formação dos professores seja orientada para uma "aprendizagem por problemas" (PERRENOUD, 2002) a fim de que os professores se confrontem com a experiência de sala de aula e trabalhem a partir de suas observações, bem como de suas dificuldades, para controlar os processos de aprendizagem e as dinâmicas de grupos ou os comportamentos de alguns alunos. Nesse ponto, seria importante um equilíbrio entre os aportes teóricos estruturados, que antecipam os problemas, e aportes mais fragmentados, que correspondem a necessidades suscitadas pela experiência.

Assim, as professoras devem engajar-se ativamente, "mobilizando o máximo de competências" 
(PERRENOUD, 2002), fazendo o que for preciso para que possam ser construídas novas competências a curto e em médio prazo, empenhando-se coletivamente, na definição de problemas, na exploração de soluções possíveis e na própria avaliação. Nesse sentido, a competência do professor pode revelar-se na transformação de uma ação educacional previamente estabelecida, em uma intervenção, frente a uma necessidade específica emergente, no contexto educacional.

Enfim, as conclusões a que cheguei, neste trabalho, não se conflituam com as propostas que se tem feito ultimamente sobre formação continuada, muito pelo contrário, a minha intenção é que elas, através de investigação da realidade, se somem e desvendam maiores dados sobre o que está acontecendo na prática escolar.

Desse modo, esta pesquisa, constitui-se num alerta para repensar a prática que vem sendo realizada nos programas de formação continuada. Tudo indica que não bastam esforços na formação prévia do professor. É preciso estender ações e influên-cias sobre o professor em exercício, favorecendo situações de análise e reflexão sobre a sua própria experiência.

\section{REFERÊNCIAS}

BOURDIEU, P. Esquisse d'une théorie de la pratique. Genebra: Droz, 1972.

ESTEVE, J. M. Mudanças sociais e função docente. In: NÓVOA, António (Org.).
Profissão professor. Porto: Publicações Dom Quixote/IIE, 1995.

GARCIA, C. M. Formação de professores: para uma mudança educativa. Porto: Porto Editora, 1997.

A formação de professores: novas perspectivas baseadas na investigação sobre o pensamento do professor. In: NÓVOA, A. (Org.). Os professores e a sua formação. Lisboa: Publicações Dom Quixote/IIE, 1997.

GERALDI, C. M. G.; MESSIAS, M. G. M.; GUERRA, M. D. S. Refletindo com Zeichner: um encontro orientado por preocupações políticas, teóricas e epistemológicas. In: GERALDI, C. M. G.; FIORENTINI, D.; PEREIRA, E. M. A. (Orgs.). Cartografias do trabalho docente: professor(a) pesquisador(a). Campinas: Mercado de Letras/ALB, 1998.

IMBERNÓN, F. Formação docente e profissional: forma-se para a mudança e a incerteza. São Paulo: Cortez, 2001.

NÓVOA, A. Formação de professores e profissão docente. In: ___ (Org.). Os professores e a sua formação. Lisboa: Publicações Dom Quixote/IIE, 1997.

O passado e o presente dos professores. In: NÓVOA, A. (Org.). Profissão professor. Porto: Publicações Dom Quixote, 1995.

Os professores e as histórias da sua vida. In: NÓVOA, A. (Org.). Vidas de professores. 2. ed. Porto: Porto Editora, 1995.

PACHECO, J. A. Currículo: teoria e práxis. Porto: Porto Editora, 1996.

PERRENOUD, P. A formação dos professores no século XXI. In: et al. (Org.). As competências para ensinar no século XXI: a formação dos professo- 
res e o desafio da avaliação. Porto Alegre: Artmed, 2002.

. A prática reflexiva no ofício de professor: profissionalização e razão pedagógica. Porto Alegre: Artmed, 2002.

Construir as competências desde a escola. Porto Alegre: Artmed, 1999.

Práticas pedagógicas, profissão docente e formação: perspectivas sociológicas. Lisboa: Publicações Dom Quixote/IIE, 1993.

PIMENTA, S. G.; GARRIDO, E.; MOURA, M. Pesquisa colaborativa na escola facilitando o desenvolvimento profissional de professores. In: REUNIÃO ANUAL DA ANPED, 24. Intelectuais, conhecimentos e espaço público, Rio de Janeiro, 2001. CD-ROM.

RODRIGUES, Â; ESTEVES, M. A análise de necessidades na formação de professores. Porto: Porto Editora, 1993.

SCHÖN, D. A. Formar professores como profissionais reflexivos. In: NÓVOA, A. (Org.). Os professores e sua formação. Lisboa: Publicações Dom Quixote/IIE, 1997.

TARDIF, M; LESSARD, C; LAHAYE, L. Os professores face ao saber: esboço de uma problemática do saber docente. Teoria e educação, Porto Alegre, n. 4, 1991.

Encaminhado em: 17/03/05

Aceito em: 11/08/05 